"NOTICE: this is the author's version of a work that was accepted for publication in Energy. Changes resulting from the publishing process, such as peer review, editing, corrections, structural formatting, and other quality control mechanisms may not be reflected in this document. Changes may have been made to this work since it was submitted for publication. A definitive version was subsequently published in Energy, Vol. 114, 465-477, http://dx.doi.org/10.1016/j.energy.2016.08.022 
Please cite as: Bertsch, V., Hall, M., Weinhardt, C., \& Fichtner, W. (2016). Public acceptance and preferences related to renewable energy and grid expansion policy: Empirical insights for Germany. Energy, 114, 465-477.

\section{Public acceptance and preferences related to renewable energy and grid expansion policy: Empirical insights for Germany}

Valentin Bertsch ${ }^{\mathrm{a}, \mathrm{b}, \mathrm{c}, \mathrm{d},{ }^{*}}$, Margeret Hall ${ }^{\mathrm{c}, \mathrm{e}}$, Christof Weinhardt ${ }^{\mathrm{c}, \mathrm{f}}$, Wolf Fichtner ${ }^{\mathrm{c}, \mathrm{d}}$

${ }^{a}$ Economic and Social Research Institute (ESRI), Whitaker Square, Sir John Rogerson's Quay, Dublin 2, Ireland

${ }^{b}$ Department of Economics, Trinity College Dublin, College Green, Dublin 2, Ireland

${ }^{c}$ Karlsruhe Service Research Institute (KSRI), Karlsruhe Institute of Technology, Englerstr. 11, 76131 Karlsruhe, Germany

${ }^{d}$ Chair of Energy Economics, Institute for Industrial Production (IIP), Karlsruhe Institute of Technology, Hertzstr. 16, 76187 Karlsruhe, Germany

${ }^{\text {e }}$ School of Interdisciplinary Informatics, University of Nebraska, Omaha, 1110 S. 67th Street, Omaha Nebraska, 68182, US

fInstitute of Information Systems and Marketing (IISM), Karlsruhe Institute of Technology, Englerstr. 14, 6131 Karlsruhe, Germany

* Corresponding author. Email address: valentin.bertsch@esri.ie

\section{Abstract}

The rapid expansion of renewable energy sources (RES) in many European countries brings about transmission grid expansion requirements. While the transition towards RESbased energy systems is largely perceived positively in general, locally both RES and grid expansion are often confronted with a lack of public acceptance. Using Germany as a case study, we analyse public acceptance of energy infrastructure and its main drivers on local vs. national levels. For this purpose, we conducted a nationally representative survey. Our results show that, on a national level, the acceptance of RES is very high and there is also a high acceptance of grid expansion if it helps to increase the share of RES in the system. In terms of local acceptance problems that may arise for most considered technologies, concerns about landscape modification turn out to be the main driving factor. Moreover, the distance between places of residence and places of energy infrastructure construction is crucial. While acceptance or rejection of technologies will never be entirely tangible or explicable, we find the explicability of rejections to be lowest for new technologies. Finally, age and education turn out to be the most relevant socio-demographic variables determining the participants' acceptance.

(C) 2016. This manuscript version is made available under the CC-BY-NC-ND 4.0 licence http://creativecommons.org/licenses/by-nc-nd/4.0/ 
Please cite as: Bertsch, V., Hall, M., Weinhardt, C., \& Fichtner, W. (2016). Public acceptance and preferences related to renewable energy and grid expansion policy: Empirical insights for Germany. Energy, 114, 465-477.

\section{Introduction}

There is little dissent that greenhouse gas emissions need to be reduced globally to combat climate change and that the decarbonisation of the energy sector is a basic prerequisite in this context [1]. In Europe, emissions are planned to be reduced to $80-95 \%$ below 1990 levels by 2050 and the decarbonisation of the energy system shall mainly be realised by energy efficiency achievements and by transforming the current system into a system based on renewable energy sources (RES). In 2050, more than two thirds of gross final European energy consumption shall be provided by RES, with an even higher share for the electricity system [2]. While the public's general attitude towards most RES technologies and RESbased energy systems is rather positive according to different surveys (e.g., $[3,4]$ ), the rapid expansion of RES in many European countries brings about local challenges concerning acceptance. On the one hand, the continuous displacement of conventional power generation through RES technologies periodically leads to local acceptance problems (see e.g., [5-8]) in spite of the positive attitude towards RES-based systems on a higher level (see e.g., $[3,9,10])$. On the other hand, since many of these new power generating facilities will be located far from the load centres (in particular new wind parks), an expansion of the transmission grid is necessary to meet the resulting transport capacity requirements. Grid expansion projects, however, face acceptance problems too (see e.g., [11-14]). Because of such recent experiences, particularly on a local level, it has been suggested increasingly often to consider public acceptance as a new key dimension of energy policy (see e.g., $[1,15-17])$. In a nutshell, the understanding as well as consideration of acceptance are undoubtedly key for energy planning. Moreover, the level of public support and acceptance seems to decrease with decreasing abstraction - from global emission reduction and decarbonisation goals over national and regional energy policy directions (e.g., towards RES-based energy systems) to the local implementation and expansion of RES and grid technologies. 
Please cite as: Bertsch, V., Hall, M., Weinhardt, C., \& Fichtner, W. (2016). Public acceptance and preferences related to renewable energy and grid expansion policy: Empirical insights for Germany. Energy, 114, 465-477.

Overall, we are therefore interested in understanding how well the energy transition is accepted on different levels of abstraction, on which level acceptance problems begin to arise and what the main drivers for people's attitudes are on these different levels. We particularly seek to answer the following research questions:

1. To which extent is the energy transition as a whole supported and how much do people agree with the overall direction of RES energy policies?

2. How does the acceptance of power systems on a national level differ from the local acceptance of individual power technologies?

3. What are the main factors driving local acceptance of energy technologies?

4. How does the subjective overall valuation of technologies differ from subjective impact assessment of these technologies w.r.t. tangible criteria, and how do these differences vary across technologies?

5. How strongly should different objectives be weighted in decisions related to national or local energy policy, and how important do people rate their subjective valuation/acceptance in comparison to traditional objectives of energy policy, namely economic impact, environmental sustainability and security of supply?

6. To which extent are the answers to the above questions related and are they related to socio-demographic characteristics?

There are many studies focussing on the acceptance of different energy technologies. Several authors have conceptually studied and defined acceptance in relation to energy technologies $[3,8,13,18-20]$. Further details are provided in section 2.1. Moreover, the acceptance of RES as a whole has been analysed in literature [7,21]. Focussing on individual technologies, Van der Horst [4], Guo et al. [6], Bell et al. [10] and Wolsink [22] studied the acceptance of wind energy whereas Battaglini et al. [11], Devine-Wright [13], Ciupuliga \& Cuppen [14] and Cotton \& Devine-Wright [23] study the acceptance of grid infrastructure. Moreover, Devine-Wright [5] analyses the acceptance of a tidal wave energy project and Gross [24] investigates the acceptance related to geothermal energy. We wish to 
Please cite as: Bertsch, V., Hall, M., Weinhardt, C., \& Fichtner, W. (2016). Public acceptance and preferences related to renewable energy and grid expansion policy: Empirical insights for Germany. Energy, 114, 465-477.

note that the acceptance of energy technologies is a field with a large and fast growing literature. Therefore, the above selection of related work cannot be comprehensive and is, to some extent, subjective of course. While the research referred to above provides detailed and valuable insights on the acceptance of individual energy technologies, our focus is on understanding acceptance and its drivers across technologies and scales - inevitably leading to a loss in detail in relation to individual technologies. Scheer et al. [25] emphasise that considering individual technologies is not sufficient for designing and implementing future energy policies and promote an approach based on generation portfolios. While we are supportive of this statement, we extend their approach in our research, inter alia, by adding a perspective on power grid expansion and infrastructure technologies since the grid and its expansion play a crucial role in future RES-based energy systems as outlined above.

With their ongoing energy transition to RES, Germany provides a particularly good use case to analyse these questions [26]. According to the German Renewable Energy Sources Act (“Erneuerbare-Energien-Gesetz", EEG), the RES share of gross electricity generation shall amount to at least $80 \%$ by 2050 . In order to meet this target, a large amount of additional RES generators, in particular wind turbines and photovoltaic (PV) modules, will need to be integrated into the existing power system and, as a result, the power grid capacities will need to be increased strongly. We therefore conducted a large nationally-representative online survey in Germany to find answers to the research questions set out above.

The remainder of this paper is structured as follows. In section 2 , we define public acceptance for this paper in order to avoid ambiguity (section 2.1). Moreover, we provide a brief summary of the survey design and structure (section 2.2) and an overview of the methods used for our analysis (section 2.3). In section 3, we present the results. In section 4, we discuss and interpret the results before we conclude the paper in section 5 . Appendix 1 provides further details concerning the structure and questions of the survey. 
Please cite as: Bertsch, V., Hall, M., Weinhardt, C., \& Fichtner, W. (2016). Public acceptance and preferences related to renewable energy and grid expansion policy: Empirical insights for Germany. Energy, 114, 465-477.

\section{Material and Methods}

While it seems to be a common understanding that a lack of public acceptance may hinder RES as well as grid expansion, the term acceptance is used in a wide variety of circumstances. Because the specific understanding and interpretation of the term strongly affects the choice and design of methods for its elicitation, we first seek to define and delimit our usage of the term within this paper (section 2.1). Subsequently, we describe the survey design and structure (section 2.2) before providing a short overview of the methods we make use of in our analysis, including a brief selection of preference elicitation methods from the field of multi-criteria decision analysis (MCDA, section 2.3).

\subsection{The term acceptance}

On a general level, acceptance can be understood as an active or passive approval of a certain technology/product or policy. Different sub-categories of acceptance have been introduced in literature. For instance, Wüstenhagen et al. [3] distinguish between sociopolitical acceptance (social acceptance on the broadest level), community acceptance (particularly referring to siting decisions of energy projects involving local authorities and residents) and market acceptance (closely related to the market adoption of innovations or products). Schweizer-Ries [19] differentiates between a valuation dimension (adoption vs. rejection) and an action dimension (passive vs. active) resulting in four quadrants in her acceptance model. For instance, a positive valuation may be expressed through either active or passive acceptance/behaviour. Focussing on technology acceptance, Schumann [20] distinguishes between different forms depending on the type of technology under consideration. For "product and everyday technology", acceptance is disclosed by (active) purchasing behaviour. This type of acceptance partly corresponds to the market acceptance described by Wüstenhagen et al. [3]. For "work technology", the active use of a technology or product (e.g., software technology) by the employees of a company reveals its acceptance. For both "product and everyday technology" as well as "work technology", acceptance is shown by an active behaviour. For large-scale technologies, including most energy technologies, the passive approval or tolerance of those concerned (e.g., as they live in the 
Please cite as: Bertsch, V., Hall, M., Weinhardt, C., \& Fichtner, W. (2016). Public acceptance and preferences related to renewable energy and grid expansion policy: Empirical insights for Germany. Energy, 114, 465-477.

area) imply the acceptance according to Schumann [20], whereas it is not necessary for those concerned to become active or to have a positive attitude towards the technology. While the definition by Schumann [20] is in line with that by Schweizer-Ries [19] in that acceptance may include passive as well as active behaviour, it differs in that Schweizer-Ries [19] does not consider a negative attitude with a passive behaviour as acceptance. While for large-scale energy technologies, an active approval is often not easily possible for "normal" citizens, this topic has also been a subject of research in individual studies (see for instance Hampl \& Wüstenhagen [27], who conceptually investigate investor acceptance of large wind power projects).

Acceptance is also often used synonymously with acceptability. Like other authors, however, we clearly distinguish between the two terms (see [20,28]): Acceptability takes into account the judgement of experts as to whether the construction of a particular facility (e.g., a power plant or transmission line) is a reasonable burden under rational consideration of quantifiable criteria (e.g., health impact or noise). Acceptance, on the other hand, is a subjective measure of the readiness of people to accept a certain facility in their neighbourhood - regardless of rational judgements.

In this paper, we focus on the acceptance rather than the acceptability. Because of our interest in (mostly) large-scale energy technologies, we do not differentiate between active and passive behaviour but focus on the valuation dimension. We therefore define acceptance for the purpose of this paper as the passive or active socio-political and community acceptance of (mostly) large-scale energy technologies or related policy strategies, i.e. the public's passive or active approval (based on subjective valuation rather than scientific expertise) of decisions by others.

\subsection{Survey design and structure}

To gain insights related to the research questions outlined in section 1, we developed an empirical survey in three iterations. In order to assess subjective perceptions and acceptance of the transition to RES, an initial questionnaire was developed based on stated preference 
Please cite as: Bertsch, V., Hall, M., Weinhardt, C., \& Fichtner, W. (2016). Public acceptance and preferences related to renewable energy and grid expansion policy: Empirical insights for Germany. Energy, 114, 465-477.

questions $^{1}$ and pre-tested with $\mathrm{n}=372$ respondents. The results of this pre-test were subjected to a Confirmatory Factor Analysis (CFA), where items not achieving a KaiserMeyer-Olkin (KMO) criterion of 0.6 or higher and a significant result in Barlett's Test of sphericity were eliminated [32,33]. This resulted in the dropping of six items from the questionnaire along with several updates of question wording. Another round of pre-testing and CFA for verifying that the changes did not alter the structure and loading of the factors was completed after the drop of these six questions and changes in wording. Gender was found to have no impact in these two iterations, and was no longer considered in the next iteration as a privacy measure.

A nationally representative panel of Germany was drawn in the final stage $(n=1443)$ using the panel book of Consumerfieldwork $\mathrm{GmbH}$, an international online consumer panel company with over 45,000 panellists across Germany. The Consumerfieldwork-delivered panel is demographically representative of age and state residence in Germany. Pages within dimension blocks, questions per page and non-ranked matrix questions were randomized to avoid order effects [34,35]. 14:45 minutes was determined to be the minimum amount of time required for questionnaire completion, and two screening questions were included in the first and second blocks of the questionnaire [36]. Participants who met all three criteria were kept in the sample $(n=996)$. Since the respondents were given the option to choose "No Response/Prefer Not to Disclose" for some questions, the sample size may differ for certain questions and analyses.

Table 1: Socio-demographic aspects of the survey population

\footnotetext{
${ }^{1}$ For a discussion on the theories and elicitation strategies behind stated and revealed preferences, see the works by [29-31].
} 
Please cite as: Bertsch, V., Hall, M., Weinhardt, C., \& Fichtner, W. (2016). Public acceptance and preferences related to renewable energy and grid expansion policy: Empirical insights for Germany. Energy, 114, 465-477.

\begin{tabular}{|c|c|c|c|c|}
\hline & Value Label & $\mathbf{n}$ & $\begin{array}{r}\% \text { of survey } \\
\text { sample }\end{array}$ & $\begin{array}{l}\% \text { German } \\
\text { population }\end{array}$ \\
\hline \multirow{3}{*}{$\begin{array}{l}\text { Population Density of } \\
\text { Residence }\end{array}$} & High & 262 & 34.7 & 57.1 \\
\hline & Medium & 281 & 37.2 & 25.4 \\
\hline & Low & 212 & 28.1 & 17.5 \\
\hline \multirow[t]{6}{*}{ Age } & $18-24$ & 69 & 9.1 & 7.7 \\
\hline & $25-34$ & 111 & 14.7 & 12.4 \\
\hline & $35-44$ & 131 & 17.4 & 12.5 \\
\hline & $45-54$ & 143 & 18.9 & 16.8 \\
\hline & $55-64$ & 111 & 14.7 & 13.3 \\
\hline & $65+$ & 190 & 25.2 & 20.8 \\
\hline \multirow[t]{7}{*}{ Highest Achieved Degree } & None & 3 & 0.4 & 3.6 \\
\hline & $\begin{array}{l}\text { Certificate of secondary modern school } \\
\text { ("Hauptschulabschluss") }\end{array}$ & 116 & 15.4 & 33.8 \\
\hline & $\begin{array}{l}\text { Secondary school leaving certificate } \\
\text { ("Realschulabschluss") }\end{array}$ & 277 & 36.7 & 27.7 \\
\hline & $\begin{array}{l}\text { Diploma from German secondary school } \\
\text { ("Fachabitur/Abitur") }\end{array}$ & 190 & 25.2 & 28.8 \\
\hline & Bachelor & 43 & 5.7 & 1.3 \\
\hline & Diploma/ Master & 119 & 15.8 & 13.5 \\
\hline & PhD or higher & 7 & 0.9 & 1.1 \\
\hline \multirow[t]{3}{*}{ Rented or Owned Dwellings } & Own & 235 & 31.1 & 44.2 \\
\hline & Rent & 505 & 66.9 & 53.6 \\
\hline & Other & 15 & 2.0 & 2.4 \\
\hline \multirow[t]{6}{*}{ Income } & $0 €-14,999 €$ & 205 & 27.2 & 18.2 \\
\hline & $15,000 €-19,999 €$ & 103 & 13.6 & 9.7 \\
\hline & $20,000 €-29,999 €$ & 177 & 23.4 & 20.8 \\
\hline & $30,000 €-44,999 €$ & 167 & 22.1 & 18.6 \\
\hline & $45,000 €-59,999 €$ & 64 & 8.5 & 16.4 \\
\hline & $60,000 €+$ & 39 & 5.2 & 16.4 \\
\hline
\end{tabular}

Table 1 illustrates the socio-demographic aspects of the survey population with the 755 respondents who did not choose "No Response/Prefer Not to Disclose" in any of the options. The final column represents 2014 national percentages of the population according to OECD 
Please cite as: Bertsch, V., Hall, M., Weinhardt, C., \& Fichtner, W. (2016). Public acceptance and preferences related to renewable energy and grid expansion policy: Empirical insights for Germany. Energy, 114, 465-477.

and DESTATIS (German Federal) statistics. We note that the age intervals are not the same as the population percentage starts at birth and this survey starts only at the age of 18 , leading to some percentage discrepancies. Zip codes were used to verify state representativeness, but are cloaked here with the variable "Population Density."

Table 2: Overview of survey question categories and research questions

Research Question Survey Question Categories

1) To which extent is the energy transition as a Category 1: whole supported and how much do people - Attitudes and perceptions related to technological agree with the overall direction of RES energy policies? change and public participation

- $\quad$ Preferences to accept different future power generation mixes (similar to [25], see Figure 7)

2) How does the acceptance of power systems

Category 2: on a national level differ from the local acceptance of individual power technologies?

- Subjective overall valuation of individual technologies and minimum distance assessment to accept technologies locally

- Comparison to selected questions in category 1

3) What are the main factors driving local Category 3:

acceptance of technologies? - Impact assessment of technologies w.r.t. different project-related criteria

- $\quad$ Rating importance of project-related criteria

4) How does the subjective overall valuation of Comparison of answers to selected questions in categories technologies differ from subjective impact 2 and 3 assessment of these technologies w.r.t. tangible criteria, and how do these differences vary across technologies?

5) How strongly should different objectives be weighted in decisions related to national or local energy policy, and how important do Category 4:

- Pairwise comparison questions aimed at rating importance of wider policy objectives people rate their subjective valuation/acceptance in comparison to traditional objectives of energy policy, namely economic impact, environmental sustainability and security of supply?

6) Are the answers to the above four questions related and are they related to sociodemographic characteristics or personal

Category 5:

Socio-demographic characteristics attitudes?

The relevant questions of our survey, aimed at answering the research questions outlined in section 1 , can be broadly grouped into five categories. Table 2 provides an overview of the research questions and the corresponding question categories. For further details, see Appendix 1 or Bertsch et al. [37]. 
Please cite as: Bertsch, V., Hall, M., Weinhardt, C., \& Fichtner, W. (2016). Public acceptance and preferences related to renewable energy and grid expansion policy: Empirical insights for Germany. Energy, 114, 465-477.

\subsection{Analysis and elicitation methods}

The results were analysed by a combination of different methods with general descriptive statistics using IBM SPSS Statistics 22 providing the basis for most question categories. These basic analyses were complemented by methods from the field of MCDA for question categories 3 and 4 of the survey as well as a multivariate analysis of covariance (MANCOVA) to analyse relations between the answers to different questions and their relation to the participants' socio-demographic information (see section 3.6). The used MCDA methods include:

- AHP ("analytic hierarchy process"): a pairwise comparison method used for question category 4 (see section 3.5).

- SWING weighting: a method to analyse the relative importance of different criteria used for question category 3 (see section 3.3).

AHP: In order to determine the relative importance of the objectives of energy policy (economic competitiveness, environmental sustainability, security of supply, public acceptance/subjective valuation), the participants were asked for pairwise comparison statements on a 9-point scale as in the analytic hierarchy process (AHP, see Saaty [38]), a method within the field of MCDA. We chose AHP since experiences have shown that people find pairwise comparisons easy to understand [39]. It should be noted, however, that the pairwise comparison procedure within AHP may lead to inconsistent preference statements. Therefore, the statements need to be checked for consistency. For this purpose, we calculated the so-called consistency ratio (CR, see [38]). Preference statements identified as inconsistent are removed from the data set for the corresponding analyses.

SWING: To determine the drivers' influence on the participants' acceptance of power technologies, we define and calculate their strength of impact based on a two-step procedure. In the first step, the participants were asked to assess the subjectively perceived impact of different conventional, RES and infrastructure technologies with respect to a selection of possible drivers on a 7-point scale; emphasising that we do not ask for rational 
Please cite as: Bertsch, V., Hall, M., Weinhardt, C., \& Fichtner, W. (2016). Public acceptance and preferences related to renewable energy and grid expansion policy: Empirical insights for Germany. Energy, 114, 465-477.

expert judgments. In the second step, the participants were requested to indicate the subjective importance of these drivers individually on a 5-point scale. On this basis, we calculated weights (normalised to sum up to one) as in SWING weighting [40,41]. The motivation for using SWING weighting for the importance elicitation of the acceptance drivers as opposed to AHP is that the set of possible drivers is much larger than the set of energy policy objectives. Experiences show that the share of inconsistent preference statements in pairwise comparison matrices increases with the amount of criteria to be compared $[42,43]$. To calculate the drivers' strength of impact, let now $n \in \mathbb{N}$ be the number of participants and $k \in\{1, \ldots, n\}$ be the participant index, let $m \in \mathbb{N}$ be the number of technologies and $j \in$ $\{1, \ldots, m\}$ be the technology index and let $l \in \mathbb{N}$ be the number of drivers and $i \in\{1, \ldots, l\}$ be the driver index. Furthermore, let $w_{i}^{k} \in[0,1]$ be the weight assigned to driver $i$ by participant $k$ and $v_{i j}^{k} \in\{-3,-2,-1,0,+1,+2,+3\}$ be the value of technology $j$ with respect to driver $i$ as perceived by participant $k$. We then define the strength of impact $s_{i j}^{k}$ of driver $i$ in determining the acceptance of technology $j$ according to participant $k$ as $s_{i j}^{k}=w_{i}^{k} \cdot v_{i j}^{k}$. Consequently, the strength of impact takes into account both, but also enables explicitly disentangling, the relative importance of a driver and the subjective impact assessment of a technology with respect to this driver.

\section{Analysis and Results}

In this section, we present the main findings from our survey. We summarise the results concerning the overall support for the decarbonisation of the energy sector and the transition towards a RES-based energy system including the acceptance of power generation mixes on a national level in section 3.1. Subsequently, we present our findings concerning the (local) acceptance of individual technologies and how this compares to the acceptance on a national level in section 3.2. We then describe the most important drivers for the acceptance of these technologies in section 3.3. We compare the results of sections 3.2 and 3.3 in section 3.4 aimed at understanding how the subjective overall valuation of technologies differs from subjective impact assessment of these technologies w.r.t. tangible criteria across 
Please cite as: Bertsch, V., Hall, M., Weinhardt, C., \& Fichtner, W. (2016). Public acceptance and preferences related to renewable energy and grid expansion policy: Empirical insights for Germany. Energy, 114, 465-477.

technologies. We present the results as regards the relative importance of policy objectives in section 3.5 before summarising our results of the socio-demographic analysis in section 3.6.

\subsection{Overall support for decarbonising the energy sector and the transition towards RES}

In the first step, our intention was to validate our initial assumption that there is little dissent in the public that greenhouse gas emissions need to be reduced. We therefore asked the participants to state how willing they are to change their lifestyle to reduce their ecological footprint and thus to express how willing they are to contribute to achieving emission reduction targets. Figure 1 shows that more than $80 \%$ of the participants were either neutral or approved this statement, which we take as a confirmation that there is consensus overall in relation to this need.

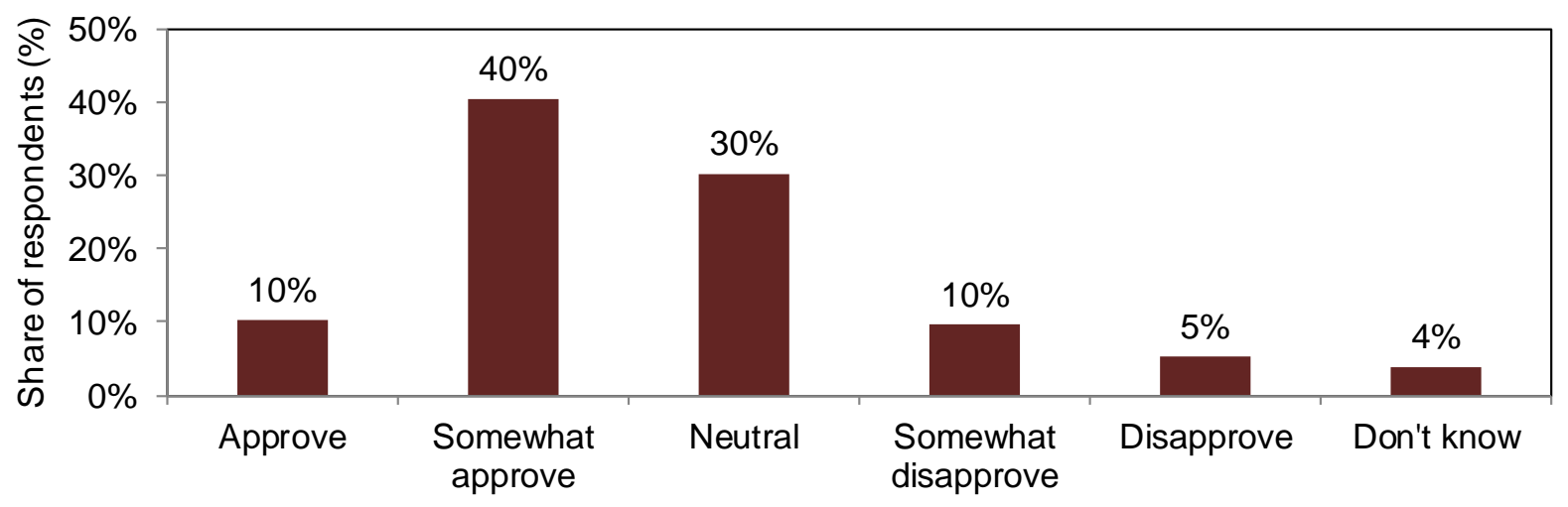

"I am ready and willing to change my lifestyle to reduce my ecological footprint"

Figure 1: Participants' overall support for decarbonising the energy sector $(n=996)$

Moreover, in order to elicit the public's support of the general policy direction towards a RESbased energy system (aimed at achieving emission reduction targets), we asked how willing they would be to accept different power generation mixes on a national level (as visualised in Figure 7 in Appendix 1) on a 5-point scale. To compare their preferences for the three offered mixes, we show the share of participants who prefer one power generation mix over another in Table 3. Both strict $(>)$ and weak $(\gtrsim)$ preferences are shown. Overall, Table 3 reveals that the acceptance of a power generation mix increases with the share of renewable power generation in the system - regardless of the required level of grid expansion. This 
Please cite as: Bertsch, V., Hall, M., Weinhardt, C., \& Fichtner, W. (2016). Public acceptance and preferences related to renewable energy and grid expansion policy: Empirical insights for Germany. Energy, 114, 465-477.

shows that, on a national level, there is a high acceptance of RES and also of power grid technologies.

Table 3: Preference relationships between power generation mixes $(n=996)$

\begin{tabular}{lcc}
\hline & Strict preference $(>)$ & Weak preference $(\gtrsim)$ \\
\hline Mix 2 vs. Mix 1 & $60 \%$ & $85 \%$ \\
Mix 3 vs. Mix 1 & $60 \%$ & $80 \%$ \\
Mix 3 vs. Mix 2 & $45 \%$ & $70 \%$ \\
\hline
\end{tabular}

\subsection{Local acceptance of individual technologies vs. acceptance of power generation mixes} In addition to ranking their acceptance of power generation mixes on a national level, participants were asked to indicate minimum distances, which must be exceeded for them to accept a certain technology in their local neighbourhood. The corresponding results are shown in Figure 2. Not surprisingly, approx. $50 \%$ of the participants responded that they would not accept a coal power plant at all (regardless of the distance). However, approx. $60 \%$ of the participants would accept grid expansion (overhead) if a minimum distance of one kilometre to their homes was guaranteed. At the same distance, wind power stations and solar PV modules would be accepted by approx. $50 \%$ and $85 \%$ of the participants respectively. Together with the result for grid expansion this is a positive outcome for the realisation of the energy transition. On the basis of the minimum distances, biomass is the least popular RES technology with distances that are very similar to those of natural gas power plants. 
Please cite as: Bertsch, V., Hall, M., Weinhardt, C., \& Fichtner, W. (2016). Public acceptance and preferences related to renewable energy and grid expansion policy: Empirical insights for Germany. Energy, 114, 465-477.
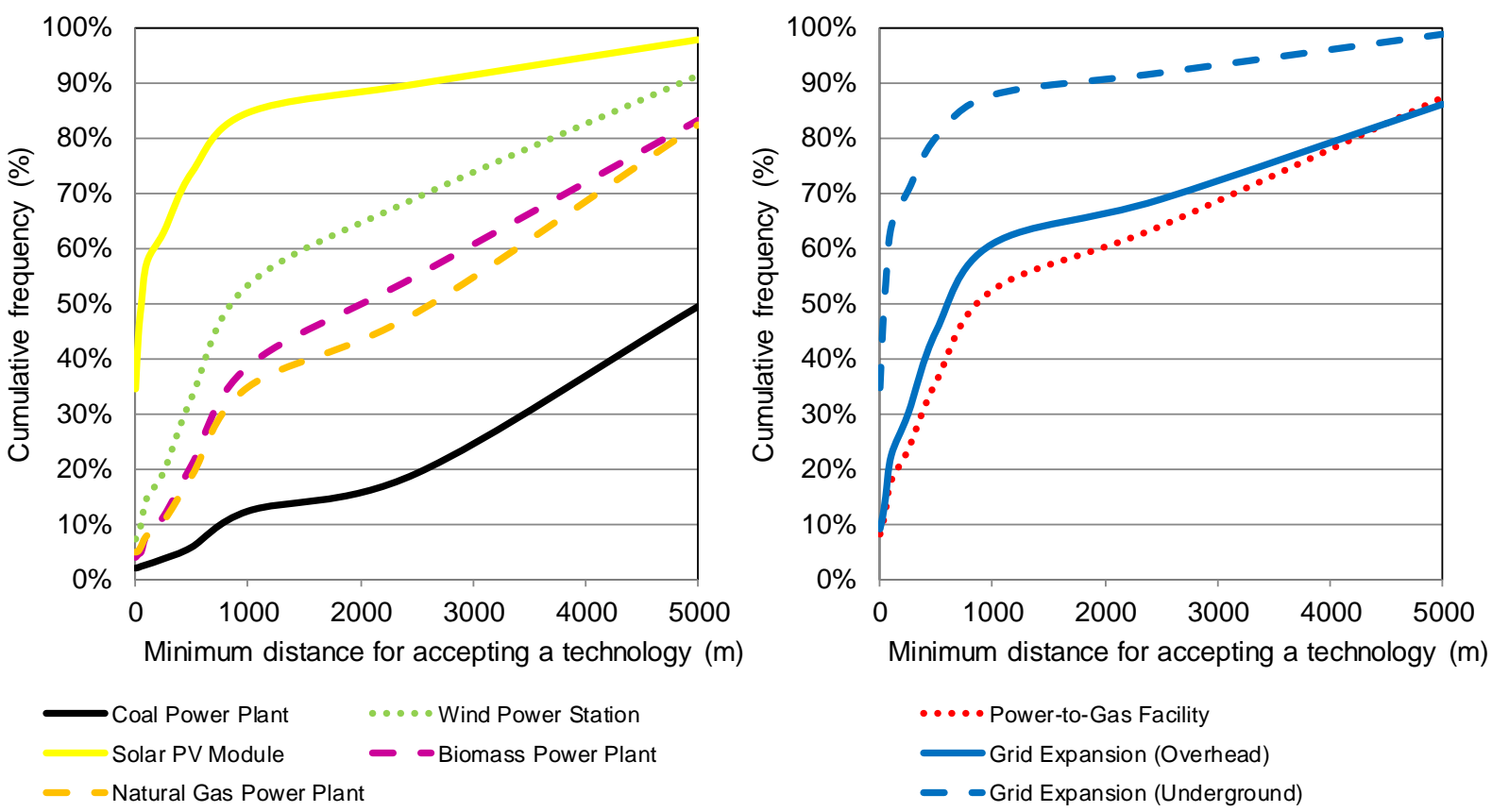

Figure 2: Minimum distances required for accepting different electricity generation (left) and infrastructure (right) technologies $(n=996)$

Comparing the distance statements with the acceptance statements for power generation mixes on a national level shows that these statements are well in line for larger distances (around $5 \mathrm{~km}$ or more, see right-hand side of both charts in Figure 2). At 5km or more, all RES and grid technologies would be accepted by at least $80 \%$ of the participants according to Figure 2. This broadly corresponds to $80 \%$ preferring Mix 3 over Mix 1 or preferring them in equal measure and $70 \%$ preferring Mix 3 over Mix 2 or preferring them in equal measure (see Table 3), where Mix 3 is the one with the highest level of RES generation (see Figure 7). For shorter distances, however, Figure 2 reveals strong differences between the acceptance on a national level and the local acceptance.

In addition to the distance statements, the participants were asked to provide their zip code. We were therefore able, in subsequent analyses, to identify areas in both Northern as well as Southern Germany, where Power-to-Gas would be accepted at comparatively low distances. We take this observation as a positive sign since in Northern Germany, Power-to-Gas plants may, to a certain extent, be beneficial for the expansion of wind power generation. In Southern Germany, the same holds true for the expansion of solar PV power generation. 
Please cite as: Bertsch, V., Hall, M., Weinhardt, C., \& Fichtner, W. (2016). Public acceptance and preferences related to renewable energy and grid expansion policy: Empirical insights for Germany. Energy, 114, 465-477.

Overall, however, the results for Power-to-Gas should be interpreted with some caution since this can be considered a rather new technology which is not yet well known by the majority of the public. This issue will be picked up again in section 3.4 and section 4 .

Beyond the distances, we were also interested in the drivers of the participants' acceptance, their importance and how they rank the different technologies with respect to these drivers. The corresponding results are presented in the next section.

\subsection{Drivers of power technology acceptance}

In order to understand which factors drive participants' acceptance of power technologies, as mentioned above (section 2.3), participants were asked to provide subjectively perceived impact assessments for the different conventional, RES and infrastructure technologies with respect to a selection of possible drivers on a seven-point Likert scale. Note that these statements, as for all stated preference surveys, may differ from rational expert judgments, as well as actual (revealed) behaviours and preferences. Subsequently, the participants were requested to judge the relative importance of these drivers aimed at calculating normalised weights. The results of the weight calculation are shown in Figure 3.

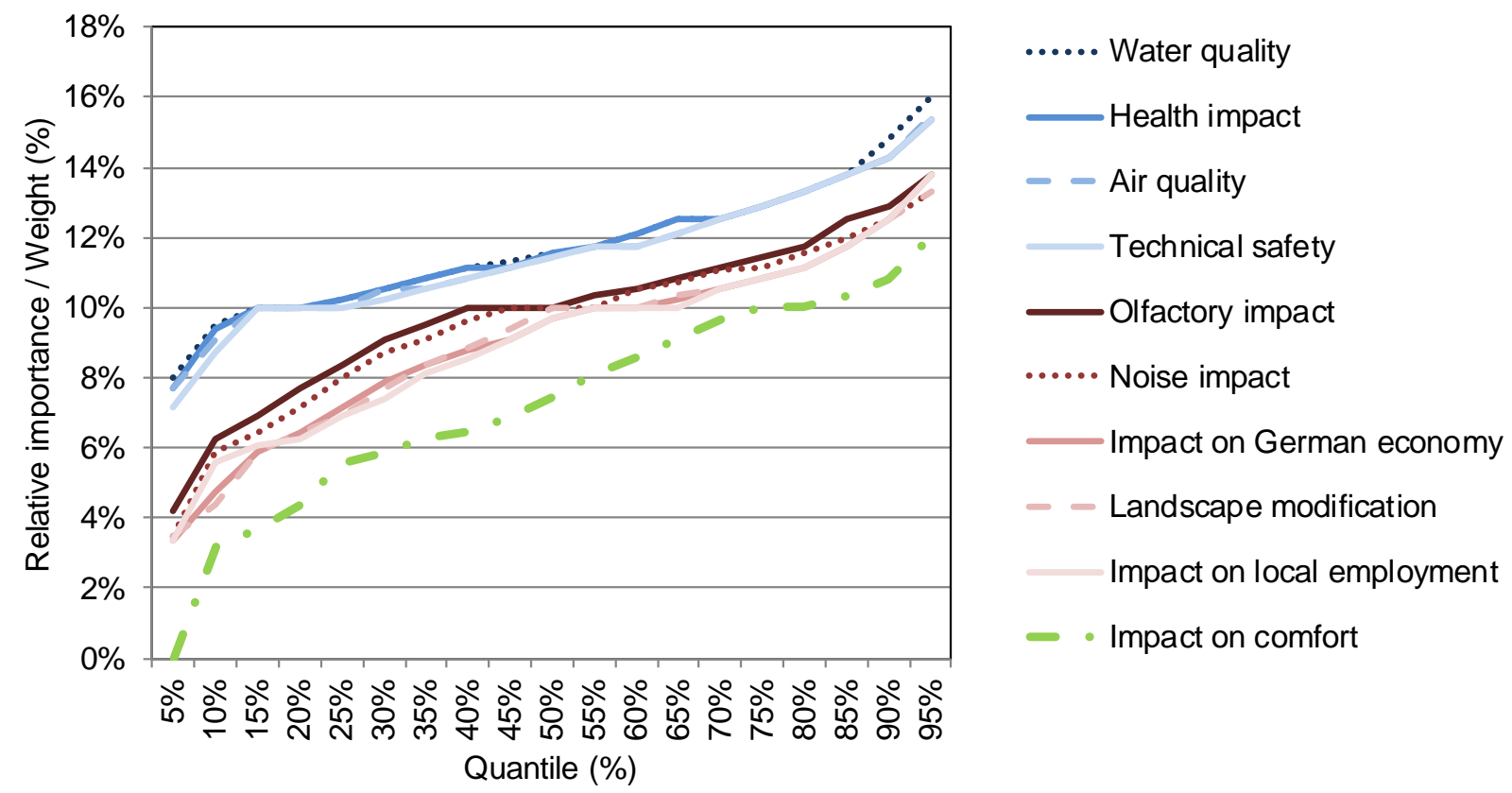

Figure 3: Relative importance of technology acceptance drivers ( $n=996)$ 
Please cite as: Bertsch, V., Hall, M., Weinhardt, C., \& Fichtner, W. (2016). Public acceptance and preferences related to renewable energy and grid expansion policy: Empirical insights for Germany. Energy, 114, 465-477.

Visually, the ten drivers offered to the participants clearly split into three categories. The drivers with the highest relative importance are water quality, health impact, air quality and technical safety followed by a group of moderate importance including olfactory impact, noise impact, impact on German economy, landscape modification and impact on local employment. Impact on comfort turns out to be the least important driver, which, again, is a positive result for the realisation of the energy transition.

In order to calculate, beyond the relative importance of drivers, their strength of impact (as defined in section 2.3), the impact assessments (see above) were multiplied by the corresponding weights. This provided the basis for identifying the drivers with the highest influence. Note that the strength of impact and the relative importance may differ. For our sample, aggregating the strength of impact over all participants shows that the most important drivers of acceptance/rejection are air quality for coal power plants, olfactory impact for biomass power plants and health impact for underground grid expansion respectively. For all other technologies, the degree of landscape modification is the single most important driver of acceptance. Further aggregating the strength of impact across all considered technologies shows the degree of landscape modification to be the most important overall driver followed by air quality and olfactory impact. The age of the respondent was found the be the most significant driver of concern about landscape modification $F(1,994)=28.087, p=.001$.

\subsection{Explicability of rejections of technologies}

In the next step of our analysis, we seek to understand how the subjective overall valuation of technologies (section 3.2) differs from subjective impact assessments of these technologies w.r.t. a selection of possible drivers (section 3.3) across the set of considered technologies. We are particularly interested in understanding to which extent rejections of technologies are 'explicable', meaning that rejected technologies are valued negatively with respect to one or several drivers. For this purpose, we checked whether the participants who responded that they reject one or more technologies according to the results illustrated in 
Please cite as: Bertsch, V., Hall, M., Weinhardt, C., \& Fichtner, W. (2016). Public acceptance and preferences related to renewable energy and grid expansion policy: Empirical insights for Germany. Energy, 114, 465-477.

Figure 2 (i.e. who would not accept one or more technologies at all, regardless of the distance to their homes), also associated a negative impact of these technologies with respect to the different drivers. We define a 'non-explicable rejection of a technology' as a technology rejection with only positive or neutral impact assessments w.r.t. all drivers. Such rejections may occur, for instance, in case of intangible preferences. We are interested in how large the shares of non-explicable rejections of technologies are and how they vary across technologies. The corresponding results are shown in Figure 4.

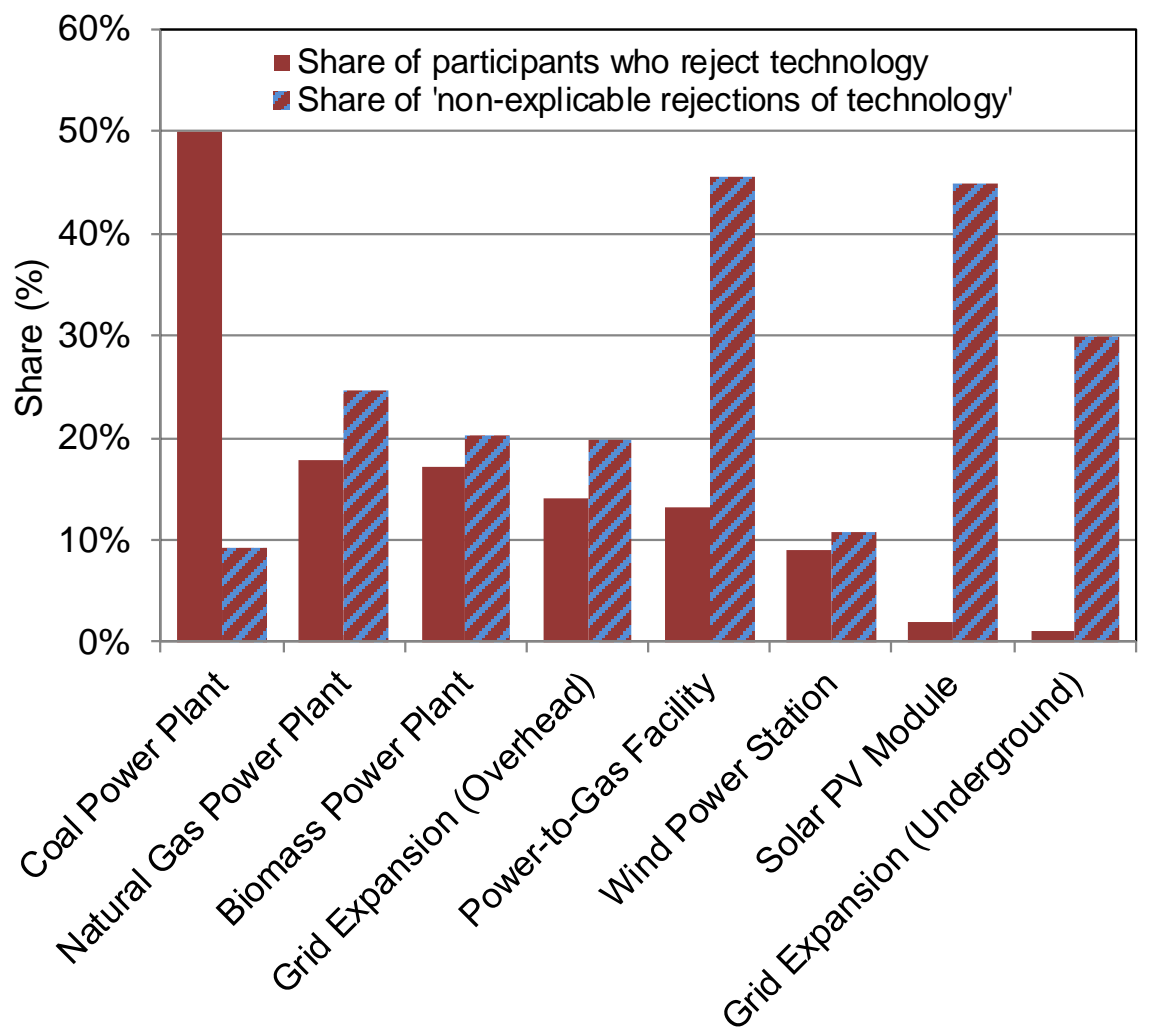

Figure 4: Shares of technology rejection and 'non-explicable' preferences

On the one hand, Figure 4 shows the total shares of participants who reject a technology (solid bars). On the other hand, the shares of non-explicable rejections are illustrated by the hatched bars (where the sample sizes for analysing non-explicable rejections are, for each technology, illustrated by the solid bars). It should be noted that the non-explicable rejections of solar PV modules and underground grid expansion are based on very small sample sizes (i.e. only very few participants would reject these two technologies regardless of the distance to their homes) so these non-explicable rejections could easily be outliers. Ignoring these two 
Please cite as: Bertsch, V., Hall, M., Weinhardt, C., \& Fichtner, W. (2016). Public acceptance and preferences related to renewable energy and grid expansion policy: Empirical insights for Germany. Energy, 114, 465-477.

technologies, Figure 4 shows a clear peak of non-explicable rejections for Power-to-Gas, while the corresponding share for coal power plants is the lowest.

\subsection{Relative importance of policy objectives}

As described in section 2.3, the calculation of the relative importance of public acceptance, economic competitiveness, environmental sustainability and security of supply follows the same procedure as in AHP, i.e. weights are derived from pairwise comparison judgments. Figure 5 shows that the resulting weights vary significantly between the participants. Moreover, Figure 5 shows the weight distributions: While the weights of security of supply and environmental sustainability are more or less evenly distributed with peaks in the lower as well as the upper parts of the entire weight ranges, the weight distributions of economic competitiveness and public acceptance are strongly right-skewed. Overall, environmental sustainability and security of supply rank much higher than public acceptance and economic impact among the German public.

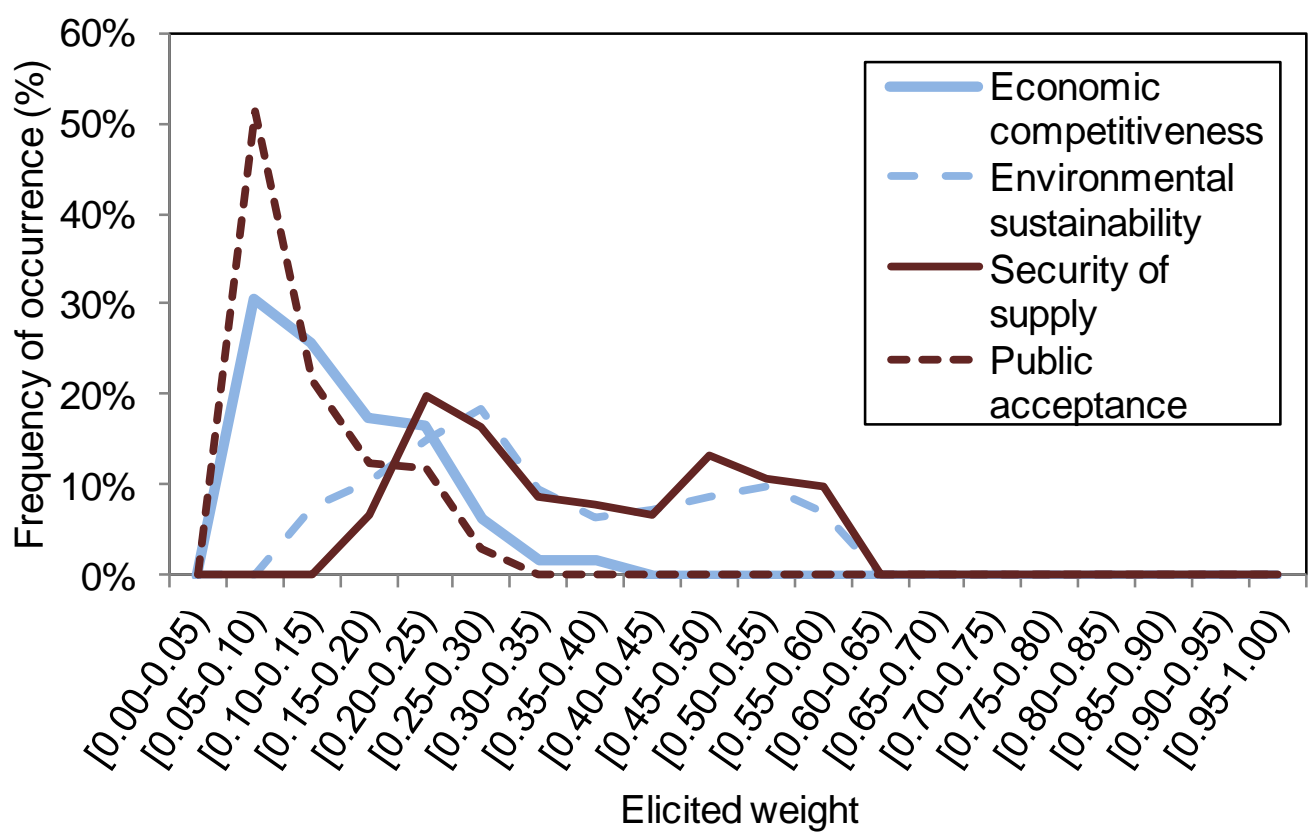

Figure 5: Empirical weight distributions resulting from the pairwise comparisons $(n=557)$

This finding, in particular the relation between environmental sustainability and economic competitiveness, is supported by similar results of a telephone survey reported by Schubert et al. [44]. Moreover, we note with interest that the weight distributions from our nationally- 
Please cite as: Bertsch, V., Hall, M., Weinhardt, C., \& Fichtner, W. (2016). Public acceptance and preferences related to renewable energy and grid expansion policy: Empirical insights for Germany. Energy, 114, 465-477.

representative survey ( $n=996$ / after removing inconsistent preference statements $n=557)$ are very similar to those from our first pre-test mentioned in section 2.2 (see Bertsch \& Fichtner [16] for details) despite different socio-demographic characteristics and sizes of the respective groups of participants.

Moreover, we wish to note that the weights are significantly negatively correlated. Particularly notable are the negative correlations between environmental sustainability and security of supply ( $\rho=-.598 / p$-value $=.000)$ and between environmental sustainability and economic competitiveness $(\rho=-.400 / p$-value $=.000)$.

\subsection{Socio-demographic characteristics}

Beyond the statements on acceptance and importance, we were interested in relations between the answers to the previously described questions and in relations to sociodemographic characteristics. For instance, we identified the following two groups who expressed a critical view on several technologies: First, a set of participants stated for all considered technologies that they either reject the technologies or would only accept these at distances larger than $5 \mathrm{~km}$. This group represents approx. $5 \%$ of all participants. Second, a set of participants responded either a rejection or an acceptance only for distances larger than $5 \mathrm{~km}$ for all RES technologies (wind, solar PV, biomass). This second group represents $10 \%$ of all participants. Participants, basically rejecting all technologies tend to rent rather than own their dwelling. Overall, $65 \%$ of the participants rent their dwellings. For the above group, the corresponding value is $73 \%$. Moreover, the level of education turned out to have an impact for the group that basically rejects all technologies: the highest graduation certificate of more than $94 \%$ of these participants is 'Abitur' (corresponding to A-levels) or lower (as opposed to $75 \%$ for the group of all participants).

Education also turned out to be a driver concerning the non-explicable rejections of technologies: on average, more than $84 \%$ of the non-explicable rejections of technologies can be traced back to participants whose highest graduation certificate is 'Abitur' or lower. 
Please cite as: Bertsch, V., Hall, M., Weinhardt, C., \& Fichtner, W. (2016). Public acceptance and preferences related to renewable energy and grid expansion policy: Empirical insights for Germany. Energy, 114, 465-477.

The individual values for wind (89\%) and overhead grid expansion (88\%) show that education is an even more important driver for these technologies.

Furthermore, we found that the location of residential areas (rural vs. urban) has an impact on the residents' acceptance. Concerning the acceptance of overhead grid expansion for instance, Figure 6 shows that residents of rural areas tend to accept grid expansion at farther distances from their dwellings than those of urban areas.

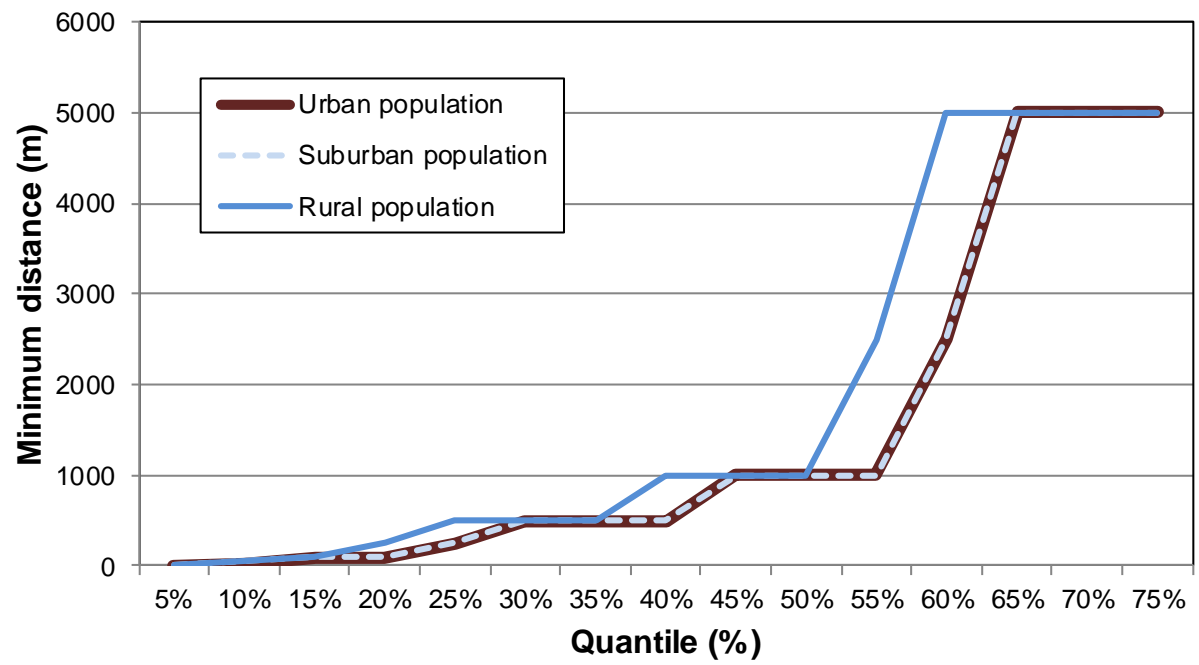

Figure 6: Differences between urban and rural population in acceptance of overhead grid expansion $(n=996)$

When we analysed the answers to the other questions and their relation to the participants' socio-demographic information, we found that the socio-demographic covariates age, income, education, population density, and if the household is rented or owned display significant differences between power generation mix acceptance and relative importance of energy policy objectives across the population. Results of a multivariate analysis of covariance (MANCOVA) reveal a strong model, with R-squared values ranging between .755 and .863 (the average model fit being .817). Age group is consistently the strongest covariate of the importance of public acceptance. Though the strength of this relationship is multiplied by population density, education level and owning or renting, these variables alone are not strong covariates. Income level also appears to play a role in the importance of preferring environmental sustainability. Income and owning one's property have the strongest impact 
Please cite as: Bertsch, V., Hall, M., Weinhardt, C., \& Fichtner, W. (2016). Public acceptance and preferences related to renewable energy and grid expansion policy: Empirical insights for Germany. Energy, 114, 465-477.

on preferring Mix 3, whereas renting, along with education level and age is a more common profile of those preferring Mix 2. A selected overview of relationships significant at $p<.05$ and higher can be found in Table 4. Preferences for economic competitiveness, security of supply, and Mix 1 were not revealed to have discernible population characteristics.

Table 4: Abbreviated results of a MANCOVA analysis of socio-demographic information, power generation mixes, and preference statements for energy policy objectives $\left(p<.05={ }^{*}, p<.01={ }^{* *}\right.$, and $\left.p<.001={ }^{* * *}\right)$

Tests of Between-Subjects Effects

\begin{tabular}{|c|c|c|c|c|c|c|c|}
\hline & & $\begin{array}{r}\text { Type III } \\
\text { Sum of } \\
\text { Squares }\end{array}$ & $\mathrm{df}^{2}$ & $\begin{array}{r}\text { Mean } \\
\text { Square }\end{array}$ & $\begin{array}{r}\text { F- } \\
\text { statistic }\end{array}$ & p-value & $\begin{array}{r}\text { Partial } \\
\text { Eta } \\
\text { Squared }\end{array}$ \\
\hline OwnRent & Mix2 & 13.141 & 3 & 4.380 & 3.856 & $.013^{*}$ & .131 \\
\hline IncomeGroup & Mix3 & 28.625 & 7 & 4.089 & 2.184 & $.045^{\star}$ & .166 \\
\hline PopDensity * AgeGroup & PubAcc & .193 & 9 & .021 & 3.149 & $.003^{* *}$ & .269 \\
\hline PopDensity * OwnRent & Mix3 & 21.231 & 2 & 10.615 & 5.668 & $.005^{\star *}$ & .128 \\
\hline AgeGroup * EductionGroup & PubAcc & .375 & 20 & .019 & 2.757 & $.001^{* * *}$ & .417 \\
\hline AgeGroup * OwnRent & Mix3 & 25.082 & 4 & 6.271 & 3.348 & $.014^{*}$ & .148 \\
\hline AgeGroup * OwnRent & PubAcc & .187 & 4 & .047 & 6.859 & $.000^{\star * *}$ & .263 \\
\hline AgeGroup * IncomeGroup & EnvSust & .991 & 29 & .034 & 2.168 & $.004^{\star \star}$ & .450 \\
\hline EductionGroup * OwnRent & Mix2 & 17.139 & 2 & 8.569 & 7.544 & $.001^{* *}$ & .164 \\
\hline EductionGroup * IncomeGroup & EnvSust & .759 & 27 & .028 & 1.782 & $.026^{\star}$ & .385 \\
\hline EductionGroup * IncomeGroup & PubAcc & .303 & 27 & .011 & 1.650 & $.046^{*}$ & .366 \\
\hline OwnRent * IncomeGroup & Mix1 & 27.127 & 5 & 5.425 & 4.198 & $.002^{* *}$ & .214 \\
\hline PopDensity * AgeGroup * IncomeGroup & Mix2 & 19.874 & 7 & 2.839 & 2.499 & $.023^{\star}$ & .185 \\
\hline AgeGroup * EductionGroup * OwnRent & Mix2 & 5.833 & 1 & 5.833 & 5.135 & $.026^{\star}$ & .063 \\
\hline $\begin{array}{l}\text { AgeGroup * EductionGroup * } \\
\text { IncomeGroup }\end{array}$ & Mix3 & 12.362 & 2 & 6.181 & 3.301 & $.042^{*}$ & .079 \\
\hline
\end{tabular}

Further descriptive aspects based on population characteristics are found concerning respondent age and income. Respondents with higher income respond more positively to the statement "I am ready and willing to pay more to support the rollout of new technologies in the energy sector" $(F(1,764)=7.355, p=.01))$, and are more likely to find that restrictions on energy usage as a conservation mechanism would prove a major impact on their daily lives $(F(1,764)=4.587, p=.05))$. It was found that the older the respondent is, the less likely they were to agree to the statements: "I am ready and willing to change my lifestyle to reduce my

\footnotetext{
${ }^{2} \mathrm{df}$ : degrees of freedom.
} 
Please cite as: Bertsch, V., Hall, M., Weinhardt, C., \& Fichtner, W. (2016). Public acceptance and preferences related to renewable energy and grid expansion policy: Empirical insights for Germany. Energy, 114, 465-477.

ecological footprint", $((F(1,882)=18.554, p=.001)$ and "I am ready and willing to pay more to support the rollout of new technologies in the energy sector" $(F(1,882)=24.159, p=$ .001)). Older respondents were also more likely to agree with the statements: "The local government has a strong influence on the planning of the local energy system" $(F(1,882)=$ 4.120, $p=.05))$ and "The government takes my opinion into consideration in the planning of the local energy system." $(F(1,882)=6.160, p=.05))$.

\section{Discussion, comparison to related work, limitations}

While we focussed on presenting the results in the previous section, we attempt to interpret them in this section and also compare our findings to existing research. The six main findings of our survey can be summarised as follows.

First, as described in the previous section, the German attitude (i) towards decarbonising the energy sector and (ii) towards the transition to RES is very positive in general. Scheer et al. [25] have analysed a similar question for Germany and for Pennsylvania in the US. Their results for Germany are in line with our finding. Moreover, they report strong differences for the US. While their Pennsylvanian sample also shows strong preferences for decarbonisation and, accordingly, for low-carbon technologies and electricity generation mixes, respondents in the US seem to prefer nuclear and carbon capture and storage (CCS) technologies as a 'solution' to the decarbonisation problem as opposed to RES technologies.

Second, in spite of the high acceptance on an abstract level, local acceptance problems may arise for most considered technologies. This finding has conceptually also been reported by Wüstenhagen et al. [3]. Focussing on wind power, Bell et al. [10] and Musall \& Kuik [9] present similar findings for the UK and southeast Germany respectively. Interestingly, Ribeiro et al. [21] report for Portugal that, with the exception of biomass, they could not find major differences between RES acceptance on an abstract vs. a local level. The lack of local acceptance is often explained by the NIMBY ('not in my backyard') phenomenon following the idea that people have a positive attitude towards something (e.g., RES expansion) until 
Please cite as: Bertsch, V., Hall, M., Weinhardt, C., \& Fichtner, W. (2016). Public acceptance and preferences related to renewable energy and grid expansion policy: Empirical insights for Germany. Energy, 114, 465-477.

they are personally confronted with the consequences (e.g., a RES or grid project in their neighbourhood) and that they then behave oppositional for selfish reasons. While we do not wish to add fuel to the fire of the NIMBY debate, it should be noted, however, that explanations based on NIMBY phenomena have been criticised as too simplistic by many researchers (see e.g., [10,13,22]). For instance, Wolsink [22] identifies fairness and equity considerations as the main determinants of local acceptance, rather than selfishness. Our analysis shows the perceived degree of landscape modification to have the highest impact on local acceptance. Worrying about landscape modification, however, cannot necessarily be classified as a selfish motive; it could just as well be driven by equity or environmental concerns or can be related to place attachment [13]. However, regardless of the motives, our results do show that the distance between places of residence and places of RES or grid technology construction is relevant (see Figure 2). According to national regulations for wind power, the minimum distance from residences to be guaranteed varies from 200-1500 metres in Germany, and 500m in Ireland to four times total turbine height and ten rotor diameters in Denmark and Scotland respectively [45]. Comparing our findings visualised in Figure 2 with the mentioned upper value of the German national regulation shows that at 1500 metres, wind turbines would be accepted by approx. $60 \%$ of the German participants. The remaining $40 \%$ would either prefer larger distances or would not be willing to accept wind power at all. Overall, however, our findings suggest that the majority of people would accept a certain level of impact by a RES or grid project.

Third, we found that the landscape modification is the most important factor driving the (lack of) local acceptance for most technologies. Similar results are reported by Van der Horst [4] for wind and biomass projects in the UK as well as Wolsink [22] for wind projects in The Netherlands. Moreover, Devine-Wright [13] mentions the impact on the landscape along with other project-related factors as an important factor for explaining the acceptance of power grid expansion in South West England. He furthermore emphasises the importance of place attachment for explaining acceptance or rejection of grid infrastructure projects. While Zoellner et al. [7] also acknowledge the importance of the landscape in their study on RES 
Please cite as: Bertsch, V., Hall, M., Weinhardt, C., \& Fichtner, W. (2016). Public acceptance and preferences related to renewable energy and grid expansion policy: Empirical insights for Germany. Energy, 114, 465-477.

acceptance for Germany, we note with interest that they find economic considerations by individuals to be yet more relevant.

Fourth, not surprisingly, the results concerning the non-explicable rejections of technologies provide proof that acceptance and rejection are not entirely explicable on a rational and quantitative basis. However, the impact of education on the discrepancy between subjective technology acceptance judgments and impact assessments of these technologies with respect to different drivers did surprise us. We note that the share of non-explicable rejections of technology is particularly high for the new technology Power-to-Gas. One possible explanation for this observation is that it is related to a lack of information and a 'fear of the unknown' (similar to what Gross [24] reports for Geothermal energy). We wish to emphasise that the conclusion in the opposite direction ('the more people know about a technology, the higher their acceptance') is not valid as our results concerning the low acceptance of coal power plants, definitively a mature and known technology, show. However, in the event that further quantitative analyses would show that Power-to-Gas is a key technology in the context of the energy transition, future acceptance research should focus on investigating whether transparent information campaigns on Power-to-Gas can help to increase the acceptance by the public (and to decrease the share of non-explicable rejections). This may apply to other new technologies analogously.

Fifth, our analysis of the relative importance of policy objectives reveals that environmental sustainability and security of supply are ranked much higher than economic competitiveness and subjective acceptance/valuation by the public. The higher importance of environmental concerns in comparison to economic considerations has also been reported by Schubert et al. [44] for Germany. However, they did not include an explicit calculation and comparison of the relative importance of economic competitiveness, environmental sustainability, security of supply and subjective acceptance/valuation in their analysis. Our results particularly reveal two large groups within the set of participants. For the first group, environmental sustainability is the most important policy objective, for the second group, it is security of 
Please cite as: Bertsch, V., Hall, M., Weinhardt, C., \& Fichtner, W. (2016). Public acceptance and preferences related to renewable energy and grid expansion policy: Empirical insights for Germany. Energy, 114, 465-477.

supply. Altogether, more than $75 \%$ of the participants indicated a weight of at least .4 to at least one of these two policy objectives. The strong and significant negative correlation between the two weights (see section 3.5) shows that the group that ranks environmental sustainability highest could be called a group of absolute supporters of the energy transition (they would even accept a decrease of the level of security of supply). Participants within the group that ranks security of supply highest are not necessarily opponents of the energy transition but for them, it is more important that the security of supply is not affected in the course of the energy transition. Furthermore, public acceptance, when considered on a national level and in a rather abstract context, is not perceived as a crucial policy objective. However, the remaining and important question in this context is whether a lack of acceptance on a local level may become a decisive factor against the realisation of individual RES or grid projects.

Sixth, age and education turned out to be the most relevant socio-demographic variables in relation to acceptance whereas age and income are the most relevant characteristics in terms of perceiving environmental sustainability as important. Comparable results concerning age and education were found by Scheer et al. [25] for Germany and the US and by Ribeiro et al. [21] for Portugal. By contrast, Devine-Wright [13] does not find a significant impact of age in driving the acceptance of energy projects. Within the group of personal variables, he finds education and length of residence to play a significant role in influencing objections to an electricity grid expansion project in the UK. Moreover, he finds place attachment to play a crucial role. When analysing the relations between socio-demographic characteristics and technology acceptance, we also found that the distances at which grid projects would be accepted are larger in rural areas in comparison to urban areas. There are several explanations for this observation. First, people living in rural areas may feel more directly affected by such a project: people in rural areas are more likely to own their dwellings and might therefore feel more directly affected in economic terms (e.g., concerning the value of their property). Moreover, most transmission grid expansion projects do affect rural rather than urban areas. Second, people in urban areas might rather feel that power grids are 
Please cite as: Bertsch, V., Hall, M., Weinhardt, C., \& Fichtner, W. (2016). Public acceptance and preferences related to renewable energy and grid expansion policy: Empirical insights for Germany. Energy, 114, 465-477.

omnipresent anyway. A new project would therefore be perceived to have little additional impact only. In other words, the 'landscape' cannot be significantly modified in urban areas whereas in rural areas it can.

To summarise the above, Table 5 provides an overview comparing a selection of our findings with those from studies in other countries as discussed in the previous paragraphs.

Table 5: Comparison of findings with related work in other countries

\begin{tabular}{|c|c|c|c|c|c|}
\hline & $\begin{array}{l}\text { Germany } \\
{[7,9,25] \text {, this }} \\
\text { study }\end{array}$ & $\begin{array}{l}\text { Netherlands } \\
{[22,46]}\end{array}$ & $\begin{array}{l}\text { Portugal } \\
{[21,47]}\end{array}$ & $\begin{array}{l}\text { UK } \\
{[4,10,13]}\end{array}$ & $\begin{array}{l}\text { US } \\
{[25,48-50]}\end{array}$ \\
\hline $\begin{array}{l}\text { High acceptance of } \\
\text { RES systems and } \\
\text { technologies in } \\
\text { general }\end{array}$ & Yes & Yes & Yes & Yes & $\begin{array}{l}\text { Yes, but nuclear } \\
\text { and CCS } \\
\text { systems are } \\
\text { preferred } \\
\text { (Pennsylvania) }\end{array}$ \\
\hline $\begin{array}{l}\text { Strong differences } \\
\text { between acceptance } \\
\text { on national vs. local } \\
\text { level }\end{array}$ & Yes & Yes & $\begin{array}{l}\text { No (with the } \\
\text { exception of } \\
\text { biomass) }\end{array}$ & $\begin{array}{l}\text { Yes, particularly } \\
\text { for wind power } \\
\text { and power grids }\end{array}$ & Yes \\
\hline $\begin{array}{l}\text { Landscape } \\
\text { modification among } \\
\text { the main drivers of } \\
\text { local acceptance }\end{array}$ & Yes & Yes & Yes & Yes & Yes \\
\hline $\begin{array}{l}\text { Driving socio- } \\
\text { demographic } \\
\text { variables }\end{array}$ & Age, education & Age & $\begin{array}{l}\text { Age, } \\
\text { education }\end{array}$ & $\begin{array}{l}\text { Education, } \\
\text { length of } \\
\text { residency }\end{array}$ & Age, education \\
\hline $\begin{array}{l}\text { Further aspects } \\
\text { affecting acceptance }\end{array}$ & $\begin{array}{l}\text { Economic } \\
\text { considerations, } \\
\text { distance } \\
\text { between } \\
\text { infrastructure } \\
\text { and homes }\end{array}$ & $\begin{array}{l}\text { Equity and } \\
\text { fairness } \\
\text { considerations }\end{array}$ & $\begin{array}{l}\text { Perception } \\
\text { of economic, } \\
\text { environment } \\
\text { al and social } \\
\text { impact of } \\
\text { technologies }\end{array}$ & $\begin{array}{l}\text { Place } \\
\text { attachment, } \\
\text { procedural } \\
\text { justice }\end{array}$ & $\begin{array}{l}\text { Distributional } \\
\text { and procedural } \\
\text { justice }\end{array}$ \\
\hline
\end{tabular}

Moreover, in addition to the above findings, we found a high acceptance of underground in comparison to overhead power grid expansion. We therefore expand the discussion around this topic in the following. Given the high acceptance of underground cable projects even at very low distances, the chances associated with an increased usage of underground cables as a grid technology should be subject to further investigations in the future. While underground cables are much more expensive than overhead lines, the low rank of economics among the policy objectives suggests that these costs should not turn out to be a major obstacle in view of the stated preferences of the German public. We do not wish to 
Please cite as: Bertsch, V., Hall, M., Weinhardt, C., \& Fichtner, W. (2016). Public acceptance and preferences related to renewable energy and grid expansion policy: Empirical insights for Germany. Energy, 114, 465-477.

imply, however, that underground cables shall be considered a silver bullet for the energy transition. There are manifold unresolved questions related to an increased usage of underground cables on the transmission grid level which need detailed investigation. For instance, the resistance of underground cables is higher than that of overhead lines, which, inter alia, has an impact on the technical losses. Moreover, for alternating current (AC) underground cables, the reactive power requirements differ strongly from overhead transmission lines. Together with the increased resistance and losses this implies a strongly reduced power transmission capacity of $A C$ underground cables in comparison to $A C$ overhead transmission lines. Underground cables should therefore only be considered a viable option for high voltage direct current (HVDC) lines. Nevertheless, in the event that this option should be considered for actual implementation, the differing technical characteristics imply the need for re-examining the transmission grid development plan, which requires additional time and may cause a delay. On the contrary, the much higher acceptance of underground cables could also be used as an argument suggesting a faster realisation of underground grid projects. We wish to emphasise that this is only likely to be true for individual planning phases because of the comparatively lower (public) opposition. As a result of the re-examination of the grid development plan, possibly including a re-consultation of the public, as well as the higher construction and maintenance effort, however, the overall time span will rather be longer. In addition, there are increasing concerns related to the many demands to utilise the geological underground more intensely in the context of the energy transition (CCS, underground gas storage, geothermal energy, underground transmission lines etc.) calling for a structured underground spatial planning and coordination aimed at ensuring a sustainable use of underground space [51,52]. This, again, is likely to rather cost time than reduce time for realising grid expansion. Finally, while the landscape modification of underground cables certainly differs from that of overhead lines, the impact seems to have been underestimated. Underground cables also bring about a massive intervention and landscape change. Moreover, findings by Gross [24] on the use of Geothermal energy suggest that the unknowns of the underground may raise suspicion among the public 
Please cite as: Bertsch, V., Hall, M., Weinhardt, C., \& Fichtner, W. (2016). Public acceptance and preferences related to renewable energy and grid expansion policy: Empirical insights for Germany. Energy, 114, 465-477.

regardless of a lower degree of landscape modification above ground. Overall, we therefore recommend more detailed investigations of landscape modification, acceptance and planning and construction time in relation to underground cables in order to be able to make an informed decision.

Critically reflecting our findings, we wish to acknowledge that the panel used for the survey is demographically representative of age and state residence in Germany. Despite the size of our sample, however, there are deviations concerning education, income and renting/owning so that the representativeness is somewhat limited. While in our sample, the share of participants with a university or technical college degree amounts to approx. $26 \%$, the corresponding share in Germany is $14 \%$. At the same time, the share of survey participants who rent their dwelling amounts to $65 \%$, whereas the corresponding share in Germany is $57 \%{ }^{3}$. Since these two socio-demographic characteristics were both found to be relevant, this information needs to be taken into account when interpreting our findings. Moreover, we are aware that, by nature, the findings of our survey are based on answers to questions, not on observations of real reactions. As described above (see section 3.3), stated and revealed preferences may diverge. In addition, particularly for new technologies (see above), the question arises to which extent the stated opinions and preferences go hand in hand with knowledge or facts related to the different technologies. On the one hand, however, as for other surveys, the participants' responses should be interpreted as educated guesses. On the other hand, our main focus is on technology acceptance and therefore on subjective perceptions rather than purely rational explanations.

\section{Conclusions and outlook}

In this paper, we provide estimates of the public acceptance of strategies for the future development of the energy system and of individual energy technologies which could be part of this future system. We were particularly interested in the overall support for the decarbonisation of the energy sector and the transition towards RES, the difference between

\footnotetext{
${ }^{3}$ see: www.destatis.de (website of the German Federal Statistical Office)
} 
Please cite as: Bertsch, V., Hall, M., Weinhardt, C., \& Fichtner, W. (2016). Public acceptance and preferences related to renewable energy and grid expansion policy: Empirical insights for Germany. Energy, 114, 465-477.

acceptance on a national vs. a local level, the individual factors driving overall acceptance, the relative importance of different policy objectives in national or local energy policy as perceived by the German public, and the relations between the answers to these questions and to the participants' socio-demographic background. For this purpose, we conducted a large nationally representative survey for Germany. Beyond existing surveys, our survey was aimed at providing an integrated overview, including the power grid and (renewable) power generation technologies since both groups of technologies are mutually dependent in the context of the energy transition.

Overall, we found that, for the majority of the German public, the acceptance of an energy system increases with an increase of the amount of renewable energy sources (RES) used in the system - despite increased power grid expansion requirements. We can therefore conclude that, on an abstract level, the majority of the German public approves the energy transition pursued by the federal government - provided that the security of supply can be maintained at a high level. This conclusion is supported by the ranking of energy policy objectives (environmental sustainability and security of supply are ranked much higher than economic competitiveness and public acceptance), the rather low distances at which RES or grid projects would be accepted and the low importance of comfort in influencing the acceptance. Locally, however, the degree of landscape modification was found to be one of the most important factors influencing the (lack of) acceptance across all considered technologies. Therefore, the question arises whether a lack of local acceptance may evolve into a 'deal-breaker'. The answer to this question, however, may be very context-specific. We also found that the attitudes (e.g., rejection) towards individual technologies sometimes cannot be explained by the corresponding importance and impact statements with respect to the influencing factors. This is particularly the case for new technologies. We identified the level of education as the differentiating socio-demographic criterion for this observation. Along with age, education also turned out to be among the most relevant socio-demographic variables driving the other results. We wish to emphasise that, in this context, education should not only be interpreted in terms of school, college or university education but also in 
Please cite as: Bertsch, V., Hall, M., Weinhardt, C., \& Fichtner, W. (2016). Public acceptance and preferences related to renewable energy and grid expansion policy: Empirical insights for Germany. Energy, 114, 465-477.

terms of knowledge or access to information about different (energy) technologies. Consequently, investment into (energy) education and transparent communication of energy strategies, emphasising that these lead to high levels of environmental sustainability and security of supply while minimising the degree of landscape modification, can help to increase the public acceptance of energy technologies and strategies.

Future research in this area should include in-depth analyses of conditions which let a lack of local acceptance evolve into a 'deal-breaker' for individual projects despite a high degree of acceptance on a national level. It could be assumed that the missing possibility for financial participation (e.g., not even being able to invest into solar PV modules) makes a difference in this regard. To analyse the relations behind in detail, however, further research is needed. Moreover, further analyses should aim at acquiring a deeper understanding of the causalities behind the observation that the group of participants basically rejecting all technologies tends to rent rather than own. More detailed investigations are also needed to take an informed decision concerning the future usage of underground cables vs. overhead lines on a transmission grid level. These should focus on comparing landscape modification, acceptance as well as planning and construction time for both options.

\section{Acknowledgements}

Valentin Bertsch acknowledges funding from the Energy Policy Research Centre of the Economic and Social Research Institute. The usual disclaimer applies. 
Please cite as: Bertsch, V., Hall, M., Weinhardt, C., \& Fichtner, W. (2016). Public acceptance and preferences related to renewable energy and grid expansion policy: Empirical insights for Germany. Energy, 114, 465-477.

\section{Appendix 1: Survey structure and questions}

\section{Category 1:}

General attitudes and perceptions related to technological change and public participation

- I am ready and willing to change my lifestyle to reduce my ecological footprint

- I am ready and willing to pay more to support the rollout of new technologies in the energy sector

- The local government has a strong influence on the planning of the local energy system

- The government takes my opinion into consideration in the planning of the local energy system

Scale of possible answers: 0 - don't know, 1 - strongly disagree, 2 - disagree, 3 - slightly disagree, 4 - neutral, 5 - slightly agree, 6 - agree, 7 - strongly agree

Preferences to accept different future power generation mixes

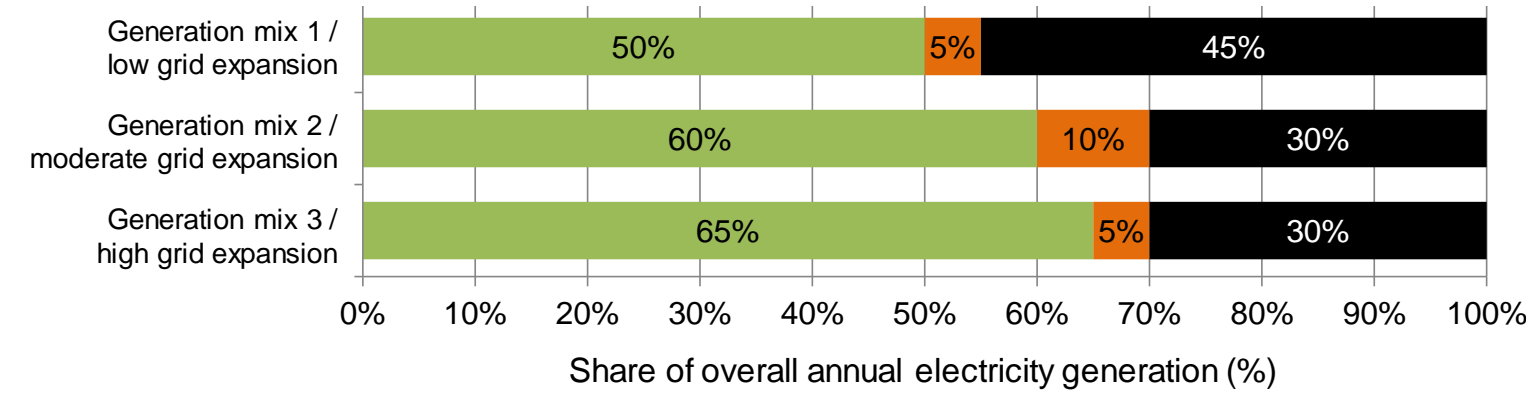

- Renewable el. generation $\quad$ El. generation from gas $\quad$ Other conventional el. generation (coal, ...)

Figure 7: Possible power generation mixes in 2030

Above, you see three different electricity generation mixes, each requiring a different level of electricity grid expansion. Please indicate your acceptance for each of these generation mixes.

Scale of possible answers: 0 - don't know, 1 - very low, 2 - low, 3 - moderate, 4 - high, 5 very high 
Please cite as: Bertsch, V., Hall, M., Weinhardt, C., \& Fichtner, W. (2016). Public acceptance and preferences related to renewable energy and grid expansion policy: Empirical insights for Germany. Energy, 114, 465-477.

\section{Category 2:}

Minimum distance assessment to accept technologies locally

Please imagine that one of the below listed facilities shall be built in your area. What should the minimum distance between your place of residence and the facility be for you to accept its construction?

- Coal Plants

- Wind Plants

- Solar Energy

- Biomass

- Natural Gas

- Power to Gas

- Overhead Power lines

- Underground Cables

Scale of possible answers: 0 - don't know, $1-0 m, 2-25 m, 3-50 m, 4-100 m, 5-250 m, 6$

$-500 m, 7-1000 m, 8-2500 m, 9-5000 m, 10-$ I would not accept the construction regardless of the distance

Category 3:

Impact assessment of technologies w.r.t. different project-related criteria

Please review each of the following technologies in terms of the listed criteria based on your personal judgment of them. Do not make comparisons between the technologies.

Technologies: Coal plants, Natural gas plants, Biomass plants, Wind power, Solar power, Power-to-Gas, Overhead lines, Underground cables, Battery storage, Demand response of automated devices 
Please cite as: Bertsch, V., Hall, M., Weinhardt, C., \& Fichtner, W. (2016). Public acceptance and preferences related to renewable energy and grid expansion policy: Empirical insights for Germany. Energy, 114, 465-477.

Criteria (subset of the following depending on technology): Impact on...

... Landscape, ... Local Jobs, ... Health, ... Air Quality, ... Noise, ... Water Quality, ... Technical Safety, ... Comfort, ... German Economy, ... Smells

Scale of possible answers: 0 - don't know, 1 - very negative, 2 - negative, 3 - slightly negative, 4 - neutral, 5 - slightly positive, 6 - positive, 7 - very positive

\section{Rating importance of project-related criteria}

Please rate how important the following aspects are for you. Impact on...

- ... Landscape

- ... Local Jobs

- ... Health

- ... Air Quality

- ... Noise

- ... Water Quality

- ... Technical Safety

- ... Comfort

- ... German Economy

- ... Smells

Scale of possible answers: $1, \ldots, 5$ (where 1 - not important / 5 - very important)

\section{Category 4:}

Pairwise comparison aimed at rating importance of wider policy objectives

Please specify which policy objective is more important to you, and give the dominance of your choice in the following scale. 
Please cite as: Bertsch, V., Hall, M., Weinhardt, C., \& Fichtner, W. (2016). Public acceptance and preferences related to renewable energy and grid expansion policy: Empirical insights for Germany. Energy, 114, 465-477.

All pairwise combinations of the following policy objectives were presented:

- Economic Competitiveness

- Environmental Sustainability

- Security of Supply

- Subjective Acceptance/Valuation by the Public

Scale of possible answers: $-9, \ldots, 0, \ldots, 9$ (where $-9=1^{\text {st }}$ objective is extremely less important than $2^{\text {nd }}$ objective, $0=$ objectives are of equal importance, $9=1^{\text {st }}$ objective is extremely more important than $2^{\text {nd }}$ objective)

\section{Category 5:}

Socio-demographic characteristics

The following socio-demographic variables were elicited: Age, Education, Income, Zip code, Renting or owning 
Please cite as: Bertsch, V., Hall, M., Weinhardt, C., \& Fichtner, W. (2016). Public acceptance and preferences related to renewable energy and grid expansion policy: Empirical insights for Germany. Energy, 114, 465-477.

\section{References}

[1] Cohen JJ, Reichl J, Schmidthaler M. Re-focussing research efforts on the public acceptance of energy infrastructure: A critical review. Energy 2014; 76:4-9.

[2] $\operatorname{COM(2011)~} 885$ (2011) Energy roadmap 2050. COM(2011) 885 final of 15 December 2011, European Union.

[3] Wüstenhagen R, Wolsink M, Bürer MJ. Social acceptance of renewable energy innovation: An introduction to the concept. Energy Policy 2007; 35(5):26832691.

[4] Van der Horst D. NIMBY or not? Exploring the relevance of location and the politics of voiced opinions in renewable energy siting controversies. Energy Policy $2007 ; 35(5): 2705-2714$.

[5] Devine-Wright P. Place attachment and public acceptance of renewable energy: A tidal energy case study. Journal of Environmental Psychology 2011; $31(4): 336-343$.

[6] Guo Y, Ru P, Su J, Anadon LD. Not in my backyard, but not far away from me: Local acceptance of wind power in China. Energy 2015; 82:722-733.

[7] Zoellner J, Schweizer-Ries P, Wemheuer C. Public acceptance of renewable energies: Results from case studies in Germany. Energy Policy 2008; 36(11):4136-4141.

[8] Raven RPJM, Mourik RM, Feenstra CFJ, Heiskanen E. Modulating societal acceptance in new energy projects: towards a toolkit methodology for project managers. Energy 2009; 34(5):564-574

[9] Musall FD, Kuik O. Local acceptance of renewable energy - A case study from southeast Germany. Energy Policy 2011; 39(6):3252-3260. 
Please cite as: Bertsch, V., Hall, M., Weinhardt, C., \& Fichtner, W. (2016). Public acceptance and preferences related to renewable energy and grid expansion policy: Empirical insights for Germany. Energy, 114, 465-477.

[10] Bell D, Gray T, Haggett C. The 'social gap' in wind farm siting decisions:

explanations and policy responses. Environmental Politics 2005; 14(4):460477.

[11] Battaglini A, Komendantova N, Brtnik P, Patt A. Perception of barriers for expansion of electricity grids in the European Union. Energy Policy 2012; 47:254-259.

[12] Steinbach A. Barriers and solutions for expansion of electricity grids - the German experience. Energy Policy 2013; 63:224-229.

[13] Devine-Wright P. Explaining "NIMBY" objections to a power line: the role of personal, place attachment and project-related factors. Environment and Behavior 2013; 45(6):761-781.

[14] Ciupuliga AR, Cuppen E. The role of dialogue in fostering acceptance of transmission lines: the case of a France-Spain interconnection project. Energy Policy 2013; 60:224-233.

[15] Hauff J, Heider C, Arms H, Gerber J, Schilling M. Gesellschaftliche Akzeptanz als Säule der energiepolitischen Zielsetzung. Energiewirtschaftliche Tagesfragen 2011; 61(10):85-87.

[16] Bertsch V, Fichtner W. A participatory multi-criteria approach for power generation and transmission planning. Annals of Operations Research 2015;1-31.

[17] Ribeiro F, Ferreira P, Araújo M. The inclusion of social aspects in power planning. Renewable and Sustainable Energy Reviews 2011; 15(9):4361-4369.

[18] Sovacool BK, Ratan PL. Conceptualizing the acceptance of wind and solar electricity. Renewable and Sustainable Energy Reviews 2012; 16(7):52685279. 
Please cite as: Bertsch, V., Hall, M., Weinhardt, C., \& Fichtner, W. (2016). Public acceptance and preferences related to renewable energy and grid expansion policy: Empirical insights for Germany. Energy, 114, 465-477.

[19] Schweizer-Ries P. Energy sustainable communities: Environmental psychological investigations. Energy Policy 2008; 36(11):4126-4135.

[20] Schumann D. Public Acceptance. In: Kuckshinrichs W, Hake J-F, editors. Carbon Capture, Storage and Use, Springer; 2015, p. 221-251.

[21] Ribeiro F, Ferreira P, Araújo M, Braga AC. Public opinion on renewable energy technologies in Portugal. Energy 2014; 69:39-50.

[22] Wolsink M. Wind power implementation: the nature of public attitudes: equity and fairness instead of 'backyard motives'. Renewable and Sustainable Energy Reviews 2007; 11(6):1188-1207.

[23] Cotton M, Devine-Wright P. Making electricity networks "visible": Industry actor representations of "publics" and public engagement in infrastructure planning. Public Understanding of Science 2010.

[24] Gross M. Old Science Fiction, New Inspiration Communicating Unknowns in the Utilization of Geothermal Energy. Science Communication 2013; 35(6):810818.

[25] Scheer D, Konrad W, Scheel O. Public evaluation of electricity technologies and future low-carbon portfolios in Germany and the USA. Energy, Sustainability and Society $2013 ; 3(1): 1-13$

[26] Fischer W, Hake JF, Kuckshinrichs W, Schröder T, Venghaus S. German energy policy and the way to sustainability: Five controversial issues in the debate on the Energiewende. Energy 2016.

[27] Hampl N, Wüstenhagen R. Management of investor acceptance in wind power megaprojects: a conceptual perspective. Organization, Technology \& Management in Construction: An International Journal 2012; 4(3):571-583. 
Please cite as: Bertsch, V., Hall, M., Weinhardt, C., \& Fichtner, W. (2016). Public acceptance and preferences related to renewable energy and grid expansion policy: Empirical insights for Germany. Energy, 114, 465-477.

[28] Renn O. Technikakzeptanz: Lehren und Rückschlüsse der Akzeptanzforschung für die Bewältigung des technischen Wandels. Technikfolgenabschätzung Theorie Und Praxis 2005; 14(3):29-38.

[29] Ben-Akiva M, Bradley M, Morikawa T, Benjamin J, Novak T, Oppewal H, Rao V. Combining revealed and stated preferences data. Marketing Letters 1994; 5(4):335-349.

[30] Carson RT, Louviere JJ. A common nomenclature for stated preference elicitation approaches. Environmental and Resource Economics 2011; 49(4):539-559.

[31] Kim SM, Pantel P, Chklovski T, Pennacchiotti M. Automatically assessing review helpfulness. 2006 Conference on Empirical Methods in Natural Language Processing (EMNLP), Sydney, Australia: Association for Computational Linguistics; 2006, p. 423-430.

[32] Bartlett MS. Properties of sufficiency and statistical tests. Proceedings of the Royal Society of London. Series A, Mathematical and Physical Sciences 1937; 160(901):268-282.

[33] Kaiser HF. A Second Generation Little Jiffy. Psychometrika 1970; 35(4):401-415.

[34] Podsakoff PM, MacKenzie SB, Lee JY, Podsakoff NP. Common method biases in behavioral research: a critical review of the literature and recommended remedies. Journal of Applied Psychology 2003; 88(5):879-903.

[35] Sills SJ, Song C. Innovations in survey research an application of web-based surveys. Social Science Computer Review 2002; 20(1):22-30.

[36] Galesic M, Bosnjak M. Effects of questionnaire length on participation and indicators of response quality in a web survey. Public Opinion Quarterly 2009; 73(2):349-360. 
Please cite as: Bertsch, V., Hall, M., Weinhardt, C., \& Fichtner, W. (2016). Public acceptance and preferences related to renewable energy and grid expansion policy: Empirical insights for Germany. Energy, 114, 465-477.

[37] Bertsch V, Fichtner W, Hall M, Schumacher T, Weinhardt C. Service Requirements for Consumer Engagement in the German Energy Retail Market. In: Zhao X, Zhang J, Han HJ, editors. Proceedings of 2015 Quality in Service (QUIS 14) 2015.

[38] Saaty TL. The Analytic Hierarchy Process. New York: McGraw Hill; 1980.

[39] Lootsma FA. Multi-Criteria Decision Analysis via Ratio and Difference Judgement. Dordrecht: Kluwer; 1999.

[40] von Winterfeldt D, Edwards W. Decision Analysis and Behavioral Research. Cambridge: Cambridge University Press; 1986.

[41] Edwards W. How to use Multiattribute Utility Measurement for Social Decision Making. IEEE Transactions on Systems, Man, and Cybernetics 1977; SMC7:326-340.

[42] Chen $\mathrm{YH}$, Wang TC, Wu CY. Multi-criteria decision making with fuzzy linguistic preference relations. Applied Mathematical Modelling 2011; 35(3):13221330.

[43] Bozóki S, Dezsö L, Poesz A, Temesi J. Analysis of pairwise comparison matrices: an empirical research. Annals of Operations Research 2013; 211(1):511528.

[44] Schubert DKJ, Meyer T, Möst D. Die Transformation des deutschen Energiesystems aus der Perspektive der Bevölkerung. Zeitschrift Für Energiewirtschaft 2015; 39(1):49-61.

[45] SLR 2014 (2014) Wind Energy: The Challenge of Community Engagement and Social Acceptance in Ireland, Report by SLR, Queen's University Belfast 
Please cite as: Bertsch, V., Hall, M., Weinhardt, C., \& Fichtner, W. (2016). Public acceptance and preferences related to renewable energy and grid expansion policy: Empirical insights for Germany. Energy, 114, 465-477.

and the University of Exeter on behalf of the National Economic \& Social Council. SLR Ref: 501.00319.00001, SLR Global Environmental Solutions.

[46] Wolsink M. Planning of renewables schemes: Deliberative and fair decision-making on landscape issues instead of reproachful accusations of non-cooperation. Energy Policy 2007; 35(5):2692-2704.

[47] Delicado A, Figueiredo E, Silva L. Community perceptions of renewable energies in Portugal: Impacts on environment, landscape and local development. Energy Research \& Social Science 2016; 13:84-93.

[48] Thayer RL, Freeman CM. Altamont: public perceptions of a wind energy landscape. Landscape and Urban Planning 1987; 14:379-398.

[49] Lantz E, Flowers L. Social Acceptance of Wind Energy Projects. Winning Hearts and Minds. State of the Art Report. Country Report of: United States. IEA Wind Task 28. 2010.

[50] Fleishman LA, De Bruin WB, Morgan MG. Informed Public Preferences for Electricity Portfolios with CCS and Other Low-Carbon Technologies. Risk Analysis 2010; 30(9):1399-1410.

[51] Bartel S, Janssen G. Underground spatial planning - Perspectives and current research in Germany. Tunnelling and Underground Space Technology 2015; 55:112-117.

[52] Martens S, Kühn M. Geological Underground will Contribute Significantly to the Implementation of the Energy Policy Towards Renewables in Germany. Energy Procedia 2015; 76:59-66. 